\title{
Early Description of the Neuroblastoma in 1815
}

\author{
Wilson IB Onuigbo* \\ Department of Pathology, Medical Foundation and Clinic, Nigeria
}

Submission: September 11, 2017; Published: December 20, 2017

*Corresponding author:Wilson IB Onuigbo, Department of Pathology, Medical Foundation and Clinic, 8 Nsukka Lane, Enugu, 400001, Nigeria, Email: wilson.onuigbo@gmail.com

\begin{abstract}
A famous textbook presented the neuroblastoma as a tumor whose peculiar metastatic pattern was recognized in 1901. Therefore, the aim of this paper is to bring to light much earlier documented case. In sum, a book published in 1815 presented the typical neuroblastomas' appearances.
\end{abstract}

Keywords: Adrenal gland; Neuroblastoma; Eponyms; History

\section{Introduction}

In his masterly compendium, "The Spread of Tumours in the Human Body," Willis [1] drew attention to the case on neuroblastoma arising primarily in the adrenal gland and tending to spread to the liver. This was so described by Pepper [2] in 1901 that the disease was named after him thereafter. Therefore, the purpose of this paper is to document a cogent historical text dating back to 1815 .

\section{Abridged Historical Text}

Farre [3] in 1815 published a book whose $7^{\text {th }}$ Case concerned a girl 3 months old on 7 th January, 1806. On the 11th, a continuance of the vomiting led to a stricter inquiry, and he was informed by the parents, that a tumour, which, on examination, was found to be situated in the left umbilical region, had appeared within a few weeks after the birth of the child, and had progressively increased to the above-mentioned period. The tumour, however, continuing to increase, pointed in several places, and proved fatal on the $7^{\text {th }}$ of March, the child's strength having rapidly sunk during the few preceding days. The following particulars were observed at the examination of the body, on the day after death. Abdomen. The intestines appeared in the epigastric region, except portions of the colon and rectum, which were pressed forward to the anterior parietes of the abdomen by a very large tumour, which originated behind the peritoneum, and enveloped the left kidney. The tumour was encysted, and its pulpy contents were compared to putrid brain. At the surface of the liver appeared swellings, which, both to the touch and eye, seemed to be in a state of complete suppuration; but this appearance was deceptive, for, an incision being made through this organ, its substance was manifestly pervaded by secondary tumours of the same structure as the large or primary tumour. Numerous cysts, varying much in size, and most intimately connected with the liver, were filled with a fungus, which broke down under very slight pressure. This substance was of a reddish-brown colour, but under maceration it soon became white, and, by expanding itself, more perfectly manifested its fungous character.

\section{Concerning the Thorax, the Findings were as Follows}

The lungs were covered with numerous prominent tubera, of a smaller size than those in the liver, containing the same morbid structure; but maceration proved that it adhered more intimately to the substance of the lungs, than it did to the liver [4].

\section{Discussion}

From the foregoing, this case pertained to the abdominal manifestations which Pepper [2] so well reported as to have been named after him. However, it suffices here that, having searched the antecedent literature an earlier case appeared. Incidentally, this was what Burnet [3] advocated with reference to beginning any field of research. Actually, this was also the view of Moser [5], who wrote in terms of pursuing the historical perspective of scientific "truth."

Incidentally, the truth here pertains to surgical pathology which the author documented elsewhere [6]. Indeed, the cellularity of elements awaited the microscope era which was in 1854 ushered in by Beale [7]. Before then, the appearances were necessarily shrouded in such terms as the liver being "filled with a fungus" or having a "fungus character." However, the natural history depicted back in 1815 was in keeping with present day knowledge of such parameters as age at diagnosis, site and sex of the child [8-10].

\section{References}

1. Willis RA (1973) The spread of tumours in the human body. Butterworths, London, UK, pp. 102. 
2. Pepper W (1901) A study of congenital sarcoma of the liver and suprarenal. Am J Med Sci 121: 287.

3. Burnet M (1977) Morphogenesis in cancer. Med J Aust 1: 5-9.

4. Farre JR (1815) Morbid anatomy of the liver. London, UK, pp, 36-38.

5. Moser KM (1987) Medical truths in historical perspective. Heart Lung 16(4): 345-346.

6. Onuigbo WIB (2015) The surgical pathology of cancer: A historical review. J Cancer Prev Curr Res 2(3): 0039.
7. Beale L (1854) The microscope and its application to medicine. Highley, London, UK, pp. 282.

8. Bodian M (1963) Neuroblastoma an evaluation of its natural history and the effects of therapy with particular reference to treatment by massive doses of vitamin $\mathrm{B}_{12}$. Arch Dis Child 38: 606-619.

9. Wilson LMK, Draper GJ (1974) Nueroblastoma, its natural history and prognosis: A study of 487 cases. Br Med J 3(5926): 301-307.

10. Alvarado CS, London WB, Look AT, Brodeur GM, Altmiller DH, et al. (2000) Natural history and biology of stage a neuroblastoma: A pediatric oncology group study. J Pediatr Hematol Oncol 22(3): 197-205.

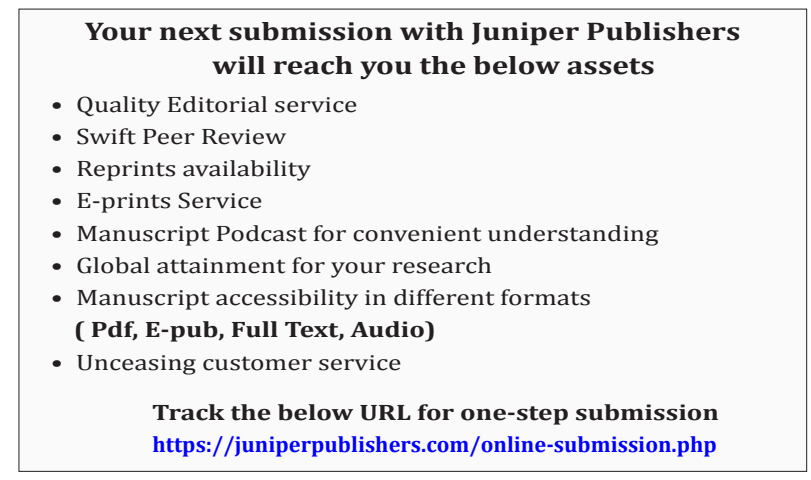

